ПАНЧЕНКО С. В., д-р техн. наук, АНАНЬСВА О. М., канд. техн. наук, ДАВИДЕНКО М. Г., канд. техн. наук, БАБАЄВ М. М., д-р техн. наук (Український державний університет залізничного транспорту)

\title{
Взаємна кореляція компонентів завад роботі тональних рейкових кіл
}

Для підвищення завадостійкості тональних рейкових кіл дочільно використовувати методологію оптимального приймання сигналів. Базовою операцією обробки вхідної адитивної сумімі сигналу й завад при такій методології є обчислення взаємної кореляційної функції ичієї суміші й опорного сигналу. Однак у изьому випадку виникають крос-кореляиійні компоненти завад, щзо впливають на підсумкові оцінки параметрів корисного сигналу й самих цุих завад. Метою даної роботи є дослідження умов, при яких зазначені кроскорелящійні компоненти мають нехтовно малий вплив на зазначені підсумкові оцінки.

Ключові слова: рейкове коло, корелячійна обробка, багатокомпонентна завада, гармоніка живильної напруги, крос-кореляція.

\section{Вступ}

Тональні рейкові кола (ТРК) набули широкого застосування на залізницях i метрополітені. Їх захищеність від впливу електромагнітних завад суттєвою мірою визначає надійність роботи систем залізничної автоматики, а відтак - безпечність руху та дотримання графіка перевізного процесу.

\footnotetext{
Аналіз досліджень та постановка задачі

Існуюча на сьогодні методологія забезпечення завадостійкості ТРК базується на їх розрахунку та конструюванні виходячи із можливої наявності завад, рівні яких із великим запасом перевищують певні розрахункові показники [1]. 3 урахуванням цього фактору обирають характеристики затухання електричних фільтрів, частоту сигнального струму, рівень цього струму та протяжність прийняття сигналу приймальним пристроєм. Останнім часом набув помітного розвитку інший підхід до аналізу завадостійкості систем, які базуються на рейкових колах та синтезі відповідних приймальних пристроїв. В основі цього підходу лежить загальна методологія оптимального прийому сигналів, яка дозволяе розвинути більш широкий та плідний погляд на забезпечення завадостійкості. Залишивши поза увагою специфіку теоретичного боку цього підходу, звернемо увагу на те, що базовою операцією обробки вхідної сигнально-завадової суміші в усіх випадках його застосування $€$ обчислення взаємної кореляційної функції цієї суміші із опорним сигналом. Випадок поодинокої завади роботі ТРК у вигляді гаусівського шуму розглянутий в роботі [2]. Більш складна ситуація, коли існуюча в рейковому колі завада $\epsilon$ двокомпонентною, проаналізована в роботі [3].
}

Розгляд оптимального прийому сигналів ТРК в умовах дії трикомпонентної завади започатковано в статті [4]. В усіх цих розробках базовим вузлом процесорного пристрою $є$ корелятор. Вдосконаленню його класичної структури присвячені роботи $[5,6]$ та багато інших. Специфікою застосування корелятора в багатозавадовій обстановці при оптимальній обробці методом сукупного оцінювання параметрів сигналу i завад $\epsilon$ вплив величин крос-кореляцій компонентів завади на підсумкову оцінку [4]. Метою даної роботи є дослідження умов, за яких вказані крос-кореляції мають нехтовно малий вплив на підсумкову оцінку параметрів сигналу ТРК.

\section{Основний матеріал}

Взаємна кореляція завади у вигляді сигналу суміжного ТРК і завади від струму промислової частоти

Позначимо амплітуду напруги сигналу як $U_{m s}$, його кутову частоту як $\omega_{s}$ та його початкову фазу як $\varphi_{s}$. Тоді міжрейкову сигнальну напругу можна записати як

$$
s(t)=U_{m s} \cdot f\left(t-\tau_{s}\right) \cdot \sin \left(\omega_{s} t+\varphi_{s}\right)
$$

де $f\left(t-\tau_{s}\right)$ є законом амплітудної модуляції сигналу:

$$
f\left(t-\tau_{s}\right)=\left\{\begin{array}{l}
1 \text { при } \tau_{s}+n T_{i} \leq t \leq \tau_{s}+\tau_{i}+n T_{i}, \\
0 \text { при інших величинах } t,
\end{array}\right.
$$

() С. В. Панченко, О. М. Ананьєва, М. Г. Давиденко, М. М. Бабаєв, 2018 
де $\tau_{i}$ - протяжність сигнального імпульсу;

$T_{i}$ - період повторення сигнальних імпульсів;

$\tau_{s}-$ часовий зсув імпульсу 3 номером $n=0$ відносно моменту часу, прийнятого за початок відліку;

$n=0, \pm 1, \pm 2, \pm 3, \ldots$.

Позначимо амплітуду завадової напруги $l$-ї гармоніки струму промислової частоти як $U_{m E l}$, а початкову фазу цієї гармоніки як $\varphi_{E l}$. Тоді міжрейкову напругу цієї завади можна записати як

$v_{E l}(t)=U_{m E l} \sin \left(l \omega_{E} t+\varphi_{E l}\right)$,

де $\omega_{E}=2 \pi 50$ рад/с.
Вважатимемо параметри сигналу та завади незмінними протягом інтервалу спостереження. Оскільки сигнал є періодичним, то загальний вираз для взаємної кореляційної функції сигналу та завади $\epsilon$ таким:

$K_{s E l}(\tau)=\frac{1}{T_{i}} \int_{\tau_{s}}^{\tau_{s}+T_{i}} s(t) v_{E l}(t-\tau) d t$

Оскільки на проміжку часу від $\tau_{s}+\tau_{i}$ до $\tau_{s}+T_{i}$ сигнал дорівнює 0 , то верхню межу інтегрування слід замінити на $\tau_{s}+\tau_{i} \cdot 3$ урахуванням цього підстановка напруг (1) та (3) у вираз (4) після нескладних перетворень призводить до такого результату:

$$
\begin{aligned}
& K_{s E l}(\tau)=\frac{U_{m s} U_{m E l} \tau_{i}}{2 T_{i}} \times\left\{\cos \frac{\left(\omega_{s}-l \omega_{E}\right)\left(2 \tau_{s}+\tau_{i}\right)+2 l \omega_{E} \tau+2 \varphi_{s}-2 \varphi_{E l}}{2} \times\right. \\
& \times \frac{\sin \left[0,5\left(\omega_{s}-l \omega_{E}\right) \tau_{i}\right]}{0,5\left(\omega_{s}-l \omega_{E}\right) \tau_{i}}-\cos \frac{\left(\omega_{s}+l \omega_{E}\right)\left(2 \tau_{s}+\tau_{i}\right)-2 l \omega_{E} \tau+2 \varphi_{s}+2 \varphi_{E l}}{2} \times \\
& \left.\times \frac{\sin \left[0,5\left(\omega_{s}+l \omega_{E}\right) \tau_{i}\right]}{0,5\left(\omega_{s}+l \omega_{E}\right) \tau_{i}}\right\} .
\end{aligned}
$$

3 останнього виразу випливає, що часова структура функції $K_{s E l}(\tau)$ являє собою синусоїдне коливання 3 частотою, яка дорівнює частоті $l$-ї гармоніки живильної мережі. Оцінимо величину амплітуди цього коливання на прикладі приймання сигналу $f 8 / 8$ (несуча частота $f_{s}=420$ Гц) на тлі 8-ї гармоніки живильного струму $\left(f_{E}=400\right.$ Гц $)$. Параметри сигналу сусіднього ТРК: $T_{i}=\frac{1}{8}$ с $\tau_{i}=0,5 T_{i}=\frac{1}{16} \quad \mathrm{c}, \quad \tau_{s}=0, \quad U_{m s}=0,062 \quad$ В (типова сигнальна напруга на відстані 135 м від генератора [1]). Амплітуда завади $U_{m E}=0,5 \mathrm{~B}$; початкові фази сигналу $\varphi_{s}$ та завади $\varphi_{E l}$ в ході розрахунків варіювалися. Як показали обчислення, за усіх можливих сполучень початкових фаз величина $K_{s E l}(\tau)$ лежить у межах від $1,3 \cdot 10^{-3} \mathrm{~B}^{2}$ до $1,45 \cdot 10^{-3} \mathrm{~B}^{2}$. Відповідно до роботи [4] цю величину слід порівнювати 3 половиною квадрату амплітуди корисного сигналу. Цей останній в тій самій точці ТРК складає $20 \cdot 10^{-3} \mathrm{~B}^{2}$, що більш ніж в 10 разів перевищує крос-кореляційну складову, обумовлену сукупною дією завади від сусіднього ТРК та завади від найближчої гармоніки живильної мережі. Вплив інших гармонік ще менший. Отже, цією складовою можна знехтувати.

Взаємна кореляція завад у вигляді сигналів ближнього ТРК та дальнього ТРК

Розглянемо типовий випадок, в якому сигнал $s_{1}$ дальнього ТРК має параметри $f 11 / 8$, а сигнал $s_{2}$ ближнього ТРК - параметри $f 9 / 12$ [1], тобто період повторення $T_{i 1}$ більший за період повторення $T_{i 2}$ відповідно до позначень, введених вище. В загальному вигляді крос-кореляційний компонент завади визначається виразом

$K_{12}(\tau)=\frac{1}{T_{i 1}} \int_{t_{1}}^{t_{2}} s_{1}(t) s_{2}(t-\tau) d t$

Інтеграл доцільно брати лише за проміжками часу, протягом яких обидва множники одночасно не дорівнюють нулю. Обмежуючись величинами $0 \leq \tau \leq \tau_{i 2}$, неважко показати, що таких проміжків два: від $\tau_{s 1}+\tau$ до $\tau_{s 1}+\tau_{i 1}$ та від $\tau_{s 1}+T_{i 1}$ до $\tau_{s 1}+T_{i 1}+\tau$ 
Тому базовий інтеграл з виразу (6) розпадається на суму двох інтегралів по кожному з визначених проміжків часу, в загальному ж вигляді з урахуванням (1) його можна записати як

$$
\begin{aligned}
& I(\tau)=\int_{t_{1}}^{t_{2}} s_{1}(t) s_{2}(t-\tau) d t=\frac{U_{m s} U_{m s 2}}{2}\left\{\frac{\sin \left[\left(\omega_{s 1}-\omega_{s 2}\right) t+\omega_{s 2} \tau+\varphi_{1}-\varphi_{2}\right]}{\omega_{s 1}-\omega_{s 2}}-\right. \\
& \left.-\frac{\sin \left[\left(\omega_{s 1}+\omega_{s 2}\right) t-\omega_{s 2} \tau+\varphi_{s 1}+\varphi_{s 2}\right]}{\omega_{s 1}+\omega_{s 2}}\right\}\left.\right|_{t_{1}} ^{t_{2}} .
\end{aligned}
$$

Підставивши в цей вираз межі першого інтервалу часу, його неважко перетворити до такого вигляду:

$$
\begin{aligned}
& I_{1}(\tau)=\frac{U_{m s 1} U_{m s 2}}{2}\left(\tau_{i 1}-\tau\right)\left[\cos \frac{\left(\omega_{s 1}-\omega_{s 2}\right)\left(2 \tau_{s 1}+\tau_{i 1}+\tau\right)+2 \omega_{s 2} \tau+2\left(\varphi_{s 1}-\varphi_{s 2}\right)}{2}\right] \times \\
& \times \frac{\sin \left[0,5\left(\omega_{s 1}-\omega_{s 2}\right)\left(\tau_{i 1}-\tau\right)\right]}{0,5\left(\omega_{s 1}-\omega_{s 2}\right)\left(\tau_{i 1}-\tau\right)}- \\
& -\frac{U_{m s 1} U_{m s}}{2}\left(\tau_{i 1}-\tau\right)\left[\cos \frac{\left(\omega_{s 1}+\omega_{s 2}\right)\left(2 \tau_{s 1}+\tau_{i 1}+\tau\right)-2 \omega_{s 2} \tau+2\left(\varphi_{s 1}+\varphi_{s 2}\right)}{2}\right] \times \\
& \times \frac{\sin \left[0,5\left(\omega_{s 1}+\omega_{s 2}\right)\left(\tau_{i 1}-\tau\right)\right]}{0,5\left(\omega_{s 1}+\omega_{s 2}\right)\left(\tau_{i 1}-\tau\right)} .
\end{aligned}
$$

Підставивши у вираз (7) межі другого інтервалу часу, його неважко перетворити до такого вигляду:

$$
\begin{aligned}
& I_{2}(\tau)=\frac{U_{m s} U_{m s 2} \tau}{2}\left[\cos \frac{\left(\omega_{s 1}-\omega_{s 2}\right)\left(2 \tau_{s 1}+2 T_{i 1}+\tau\right)+2 \omega_{s 2} \tau+2\left(\varphi_{s 1}-\varphi_{s 2}\right)}{2}\right] \times \frac{\sin \left[0,5\left(\omega_{s 1}-\omega_{s 2}\right) \tau\right]}{0,5\left(\omega_{s 1}-\omega_{s 2}\right) \tau}- \\
& -\frac{U_{m s} U_{m s 2} \tau}{2}\left[\cos \frac{\left(\omega_{s 1}+\omega_{s 2}\right)\left(2 \tau_{s 1}+2 T_{i 1}+\tau\right)-2 \omega_{s 2} \tau+2\left(\varphi_{s 1}+\varphi_{s 2}\right)}{2}\right] \times \frac{\sin \left[0,5\left(\omega_{s 1}+\omega_{s 2}\right) \tau\right]}{0,5\left(\omega_{s 1}+\omega_{s 2}\right) \tau} .
\end{aligned}
$$

А відтак крос-кореляційний компонент завад у вигляді сигналів ближнього та дальнього ТРК матиме вигляд

$K_{12}(\tau)=\frac{\left[I_{1}(\tau)+I_{2}(\tau)\right]}{T_{i 1}}$.

Ïi $\begin{array}{ccc}\text { Пасова структура цієї функції є досить складною. } \\ \text { приклад при параметрах }\end{array}$ $U_{m s 1}=U_{m s 2}=0,062 \mathrm{~B}, f_{1}=580$ Гц, $f_{2}=480$ Гц, $T_{i 1}=\frac{1}{8} \mathrm{c}, T_{i 2}=\frac{1}{12} \mathrm{c}, \tau_{s 1}=\tau_{s 2}=10^{-10}$ с та нульових початкових фазах наведений на рис. 1. За усіх можливих сполучень початкових фаз компонент $K_{12}(\tau)$ є величиною, що не перевищує $10^{-4} \mathrm{~B}^{2}$.

Відповідно до роботи [4] цю величину слід порівнювати 3 половиною квадрату амплітуди корисного сигналу, яка в тій самій точці ТРК складає $20 \cdot 10^{-3}$ В. Отже, в реальних умовах розглянутою кроскореляцією можна знехтувати. 


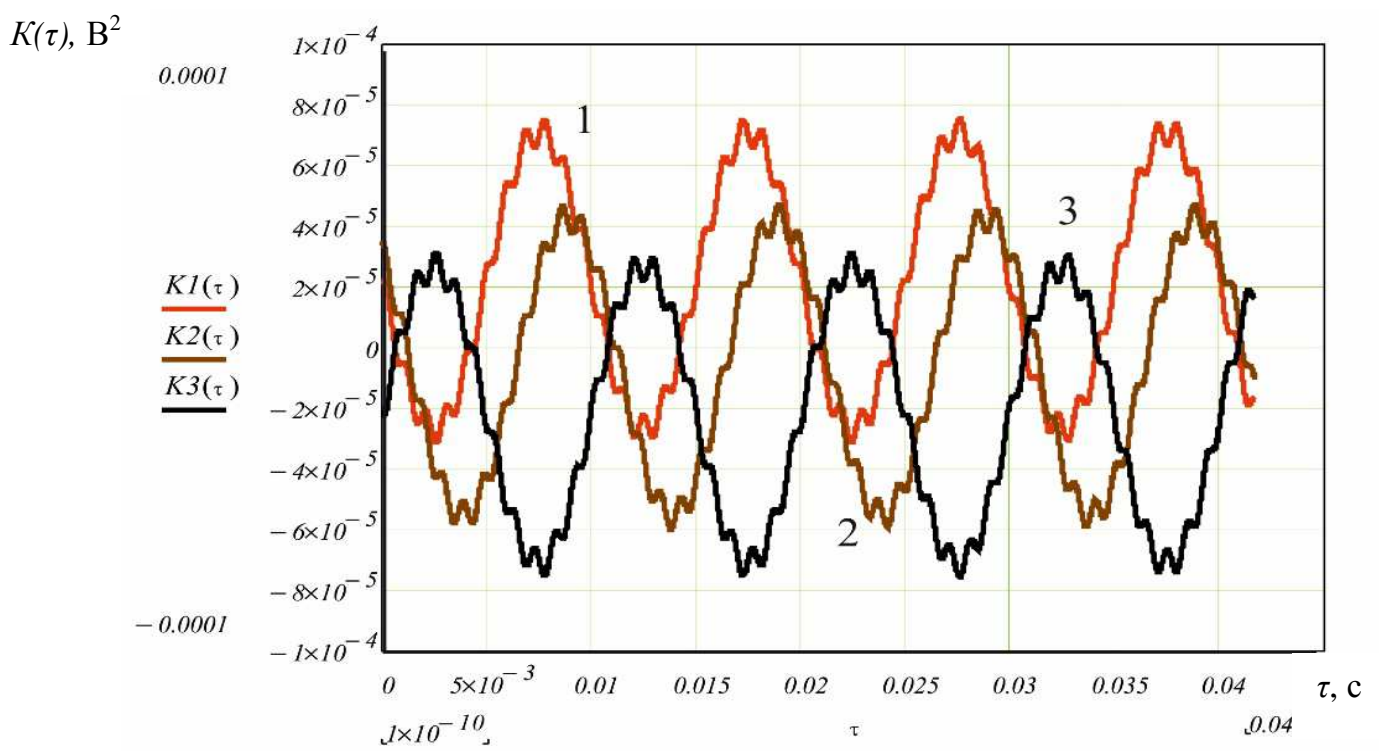

Крива 1 - для $\varphi_{s 2}=0 ;$ крива $2-$ для $\varphi_{s 2}=25^{0} ;$ крива $3-$ для $\varphi_{s 2}=90^{0}$.

Рис. 1. Взаємна кореляція завад від ближнього та дальнього ТРК

\begin{abstract}
Висновки
Показано, що утворювані при оптимальній обробці сигналів ТРК методом сукупного оцінювання параметрів сигналів і завад крос-кореляційні компоненти характерних завад мають нехтовно малі величини порівняно з іншими доданками виразу, що підлягає оптимізації. В подальших дослідженнях доцільно розглянути можливість спрощення засобів обробки сигналів, обумовлену врахуванням виявленого факту.
\end{abstract}

\section{Список використаних джерел}

1. Кулик, П.Д. Тональные рельсовые цепи в системах ЖАТ: построение, регулировка, обслуживание, поиск и устранение неисправностей, повышение эксплуатационной надежности [Текст] / П. Д. Кулик, Н. С. Ивакин, А. А. Удовиков. - К.: Издательский дом «Мануфактура», 2004. - 288 с.

2. Гончаров, К. В. Корреляционный путевой приемник тональных рельсовых цепей [Текст] / К. В. Гончаров // Вісник Дніпропетр. нац. ун-ту залізн. трансп. - Дніпропетровськ: ДНУЗТ, 2011. Вип. 38. - С. 188 - 193.

3. Ananieva, O. Design of a device for optimal reception of signals against the background of a two-component Markov interference [Text] / O. Ananieva, M. Babaiev, V. Blyndiuk, M. Davidenko // EasternEuropean Journal of Enterprise Technologies. No. 6/9 ( 90 ), 2017. - P.4 - 9.
4. Ананьева, О. М. Приём информационных сигналов систем железнодорожной автоматики в условиях действия трёхкомпонентной помехи [Текст] / О. М. Ананьева // Інформаційно-керуючі системи на залізничному транспорті. - 2018. № 1. - C. 24-28.

5. Torres J., Digital Demodulator for BFSK Waveform Based Upon Correlator and Differentiator Systems [Text] / J. Torres, F. Phernandes, J. Habermann // Radioengineering. - 2014. - Vol. 23, Issue 4. P. 1161-1168.

6. Ouyang X., Time Delay Estimation Using Windowed Differential Magnitude of Cross Correlation and Its Hilbert Transform [Text] / X. Ouyang, L. Luo, J. Xiong // Procedia Engineering. - 2012. - Vol. 29. P. 2033-2038. doi: 10.1016/j.proeng.2012.01.257.

Панченко С. В., Ананьева О. М., Давиденко М. Г., Бабаев М. М. Взаимная корреляция компонентов помех работе тональных рельсовых цепей. Для повышения помехоустойчивости тональных рельсовых цепей целесообразно использовать методологию оптимального приема сигналов. Базовой операцией обработки входной аддитивной смеси сигнала и помех при такой методологии является вычисление взаимной корреляционной функции этой смеси и опорного сигнала. Однако в этом случае возникают кросскорреляционные компоненты помех, влияющие на итоговые оценки параметров полезного сигнала и самих этих помех. Целью данной работы является исследование условий, при которых указанные 
кросс-корреляционные компоненты имеют пренебрежимо малое влияние на указанные итоговые оценки.

Ключевые слова: рельсовая цепь, корреляционная обработка, многокомпонентная помеха, гармоника питающего напряжения, кросс-корреляция.

Panchenko S., Ananieva O., Davidenko M., Babaiev M. Mutual correlation of components of interferences to work of tonal rail circuits. Tonal rail circuits work in the conditions of simultaneous influence of interferences of different type. These interferences in some cases lead to failures in operation of traveling receivers. For increase in their noise stability it is reasonable to use methodology of optimum reception of signals. Basic operation of processing of entrance additive mix of signal and interferences at such methodology is calculation of mutual correlation function of this mix and basic signal. However in this case there are cross-correlation components of interferences influencing final estimates of parameters of useful signal and these interferences. The purpose of this work is the research of conditions under which the specified cross-correlation components have negligible influence on the specified final estimates. It is shown that in the conditions of regular operation of rail circuits such influence really is negligible. Need of consideration of ways of simplification of means of processing of information signals taking into account the opportunities given by the elicited fact is noted.

Keywords: rail circuit, correlation processing, multicomponent interference, harmonic of power voltage, cross-correlation.
Панченко Сергій Володимирович, доктор технічних наук, професор, ректор, Украӥнський державний університет залізничного транспорту, Харків, Україна.E-mail: info@kart.edu.ua

ORCID: https://orcid.org/0000-0002-7626-9933

Ананьсва Ольга Михайлівна, канд. техн. наук, дочент, кафедра автоматики та комп'ютерного телекерування рухом поӥздів Украӥнського державного університету залізничного транспорту, м. Харків, Україна. E-mail: romashka13052015@gmail.com

ORCID: http://org/0000-0001-6686-8249

Давиденко Михайло Георхійович, канд. техн. наук, дочент, кафедра електроенергетики, електротехніки та електромеханіки Українського державного університету залізничного транспорту, м. Харків, Україна. E-mail: davdenk@kart.edu.ua

ORCID: http://org/0000-0001-7255-3059

Бабаєв Михайло Михайлович, д-р техн. наук, професор, завідуючий кафедри електроенергетики, електротехніки та електромеханіки Українського державного університету залізничного транспорту, м. Харків, Україна. E-mail: mmbxiit@gmail.com ORCID: http://org/0000-0003-3553-8786

Sergii Panchenko, Dr. Tech. Science, professor, rector, Ukrainian State University of Railway Transport, Kharkiv, Ukraine.E-mail: info@kart.edu.ua

ORCID https://orcid.org/0000-0002-7626-9933

Olha Ananieva, PhD, Associate Professor, Department of automation and computer-integrated technologies Ukrainian State University of Railway Transport, Kharkiv, Ukraine. E-mail: romashka13052015@gmail.com ORCID: http://orcid.org/0000-0001-6686-8249

Mykhailo Davidenko, PhD, Associate Professor, Надійшла 30.04.2018 p. Department of of electroenergy, electrical equipment and electromecanics Ukrainian State University of Railway Transport, Kharkiv, Ukraine. E-mail: davdenk@kart.edu.ua

ORCID: http://orcid.org/0000-0001-7255-3059

Mykhailo Babaiev, Doctor of Technical Sciences, Professor, Department of electroenergy, electrical equipment and electromecanics Ukrainian State University of Railway Transport, Kharkiv, Ukraine. E-mail: mmbxiit@gmail.com

ORCID: http://orcid.org/0000-0003-3553-8786 